\title{
Experimental Study of the Influence of Different Liquids on the Transformer Cooling Performance
}

DOI:

10.1109/TPWRD.2019.2895533

\section{Document Version}

Accepted author manuscript

Link to publication record in Manchester Research Explorer

\section{Citation for published version (APA):}

Daghrah, M., Wang, Z., Liu, Q., Hilker, A., \& Gyore, A. (2019). Experimental Study of the Influence of Different Liquids on the Transformer Cooling Performance. IEEE Transactions on Power Delivery, 34(2), 588-595.

https://doi.org/10.1109/TPWRD.2019.2895533

\section{Published in:}

IEEE Transactions on Power Delivery

\section{Citing this paper}

Please note that where the full-text provided on Manchester Research Explorer is the Author Accepted Manuscript or Proof version this may differ from the final Published version. If citing, it is advised that you check and use the publisher's definitive version.

\section{General rights}

Copyright and moral rights for the publications made accessible in the Research Explorer are retained by the authors and/or other copyright owners and it is a condition of accessing publications that users recognise and abide by the legal requirements associated with these rights.

\section{Takedown policy}

If you believe that this document breaches copyright please refer to the University of Manchester's Takedown Procedures [http://man.ac.uk/04Y6Bo] or contact uml.scholarlycommunications@manchester.ac.uk providing relevant details, so we can investigate your claim.

\section{OPEN ACCESS}




\title{
Experimental Study of the Influence of Different Liquids on the Transformer Cooling Performance
}

\author{
Muhammad Daghrah, Zhongdong Wang, Member, IEEE, and Qiang Liu, Member, IEEE, Andree \\ Hilker, Attila Gyore, Member, IEEE
}

\begin{abstract}
1
2 Abstract-Mineral oil is traditionally used in liquid immersed 49

3 transformers to act as a coolant, an information carrier, and as

4 an electrical insulator. Emerging alternative transformer liquids

5 provide advantages, such as improved fire safety and better

6 biodegradability, of which transformer operators would like to

7 utilize. In this paper, an experimental study is conducted to

8 compare the thermal performance of a mineral hydrocarbon

9 transformer oil, a gas-to-liquid hydrocarbon transformer oil, and

10 a synthetic ester transformer liquid as coolants in a zig-zag disc

11 type winding model. Comparisons are made under liquid

12 directed cooling modes and under liquid natural cooling modes.

13 It was found that under both cooling modes, the mineral based

14 transformer oil and the gas-to-liquid based transformer oil

15 behaved almost with comparable liquid flow and temperature

16 distributions. Under liquid directed cooling modes, the synthetic

17 ester gave more uniform flow distribution and delayed the

18 occurrence of liquid reverse flow compared to the other oils.

19 Under liquid natural cooling modes and using the zig-zag disc

20 type winding model, synthetic ester due to its higher viscosity

21 caused lower inlet flow rate to develop under the specific tested

22 retrofilling conditions which resulted in less uniform oil flow

23 distribution within the pass and higher hot spot temperature.
\end{abstract}

24 Index Terms-Transformer, Experiment, Particle Image 25 Velocimetry, Mineral Oil, Gas-To-Liquid Oil, Synthetic Ester

26

\section{INTRODUCTION}

$\mathrm{T}_{\mathrm{s}}$ ransformer life expectancy is affected by the ageing of paper insulation within the winding, which is determined 29 by its experienced temperature. The hot spot temperature 30 (HST) can be defined as the hottest temperature in the 31 transformer winding structure which causes the severest paper 50 32 ageing. In disc type power transformers, liquid is circulated 51 33 through cooling ducts within the transformer winding to 52 distribution is affected by pass inlet Reynold number (Re), 34 transport heat from within the winding to the external cooling 53 and by the winding geometries such as the radial cooling duct 35 medium. The thermal and physical properties of the liquid, 54 height $\left(H_{d}\right)$, the axial cooling duct width $\left(W_{d}\right)$, and the 36 such as density $(\sigma)$, kinematic viscosity $(v)$, thermal 55 number of discs per pass [4, 5]. Under Liquid Natural (ON or 37 conductivity $\left(k_{c}\right)$, and specific heat $\left(C_{p}\right)$, influence its cooling $\left.56 \mathrm{KN}\right)$ cooling modes, the developed liquid flow rate is affected 38 performance $[1,2]$. Cooling performance is characterized by 57 by the thermosyphon pressure induced forces within the 39 first the heat transfer coefficient, which is a local cooling 58 winding structure and the total pressure loss within the 40 factor, and second by liquid flow distribution within the 59 transformer hydraulic loop [6-8].

41 winding, which is a global cooling factor [3].

42 This Manuscript received on xx xx xxxx.

43 Muhammad Daghrah, Zhongdong Wang and Qiang Liu are with the

60 Mineral oils are traditionally used as the insulating and 61 cooling media in power transformers. Recently alternative 62 transformer liquids, such as ester based liquids and gas-to44 School of Electrical and Electronic Engineering at The University of 63 liquid based oils, emerged as alternatives in power 45 Manchester, Manchester, M13 9PL, UK (e-mail: zhongdong.wang@ 64 transformers compared to mineral oils. Ester based liquids are 46 manchester.ac.uk)

47 Adree Hilker is with Shell Global Solutions (Deutschland) - GmbH

48 Attila Gyore is with M\&I Materials, Manchester, M32 0ZD, UK
65 biodegradable and have high flash and fire points. A 66 comparison was made for the thermal performance of a 50 
$1 \mathrm{MVA}, 141 \mathrm{kV} / 13 \mathrm{kV}$ transformer that was filled in with 57 desired. The pressure loss over the winding model $\left(P_{L}\right)$ is 2 mineral oil and natural ester [9]. It was reported that under 58 measured under directed cooling mode using differential 3 KNAN cooling mode an increase in the $H S T$ by $12^{\circ} \mathrm{C}$ was 59 pressure sensors with $\pm 10 \mathrm{~Pa}$ accuracy. The liquid is heated 4 observed in the low voltage winding when filled with natural 60 within the winding model and circulated through the radiator 5 ester compared to when filled with mineral oil. Hence, it was 61 to be cooled down. To control the winding bottom liquid 6 concluded that retrofilling transformers designed for mineral 62 temperature $\left(T_{B}\right)$, an external controlled heater was connected 7 oil with natural ester requires careful considerations. The 63 in series with the winding model. The winding model consists 8 impact of mineral oils and ester based liquids on transformer 64 of 3 passes, where each pass consists of 10 aluminium plates 9 winding temperatures was investigated [10]. It was observed 65 modelling disc segments [5, 15-17]. Each plate was made with 10 that when using ester liquid the flow velocities within radial 66 dimensions $100 \mathrm{~mm} \times 104 \mathrm{~mm} \times 10 \mathrm{~mm}$, and can be heated 11 cooling ducts were lower, compared to when using mineral 67 using two resistive cylindrical heaters embedded within the 12 oil, which was the reported reason for the increase in the 68 plate. Power losses $\left(P_{\text {loss }}\right)$ in plates are controlled. 13 winding temperatures. A $15 \mathrm{MVA}$, single phase, $154 \mathrm{kV} / 22.969$ Thermocouples were used to record average plate $14 \mathrm{kV}$ transformer was filled with mineral oil and then with 70 temperatures within the winding model with accuracy $\pm 1{ }^{\circ} \mathrm{C}$. 15 natural ester [11]. Temperature rise tests were conducted and 71 Each plate was embedded with two thermocouples and their 16 an increase of near $16{ }^{\circ} \mathrm{C}$ in recorded $H S T$ was observed in the 72 average is used as a representative average plate temperature. 17 low voltage winding after retrofilling using natural ester. 73 The winding model was constructed from polycarbonate 18 Though it was indicated that ester filled transformer would 74 sheets and the sheets were milled to create $H_{d}=4 \mathrm{~mm}$ and $W_{d}$ 19 have the same expected life despite it operates at higher $H S T \quad 75=10 \mathrm{~mm}$. Particle Image Velocimetry (PIV) system was used 20 compared to the expected life when the transformer is filled 76 to measure liquid flow rates within radial cooling ducts of the 21 with mineral oil. A model for a 66 MVA, 225/26.4 kV 77 third pass in the winding model. The PIV system consists of 22 transformer was studied both experimentally and numerically 78 dual head laser source, laser optics, a camera, a synchronizer, 23 with 3D CFD simulations under ON cooling regime [12]. 79 and a software to process captured images [18]. The PIV 24 Better prediction accuracy was achieved when simulating a 80 system records velocities by tracking the movement of seeding $253 \mathrm{D}$ domain exclusive only to the winding structure and setting 81 particles within the flow. The seeding particles used in this 26 up the boundary conditions from experimental measurements 82 study were silver coated hollow gas spheres with diameter 27 of winding inlet oil flow and inlet temperature. In [13], oil 83 range from 10 to 14 microns. The laser source fires two 28 flow measurements were conducted using optical methods 84 consecutive pulses with known time difference and the camera 29 under OD cooling modes with tests conducted under pass inlet 85 captures correspondingly two raw images. Using the time 30 Reynold numbers from 667 to 4000 . The winding geometries 86 difference between the two laser pulses and the seeding 31 were 6 plates/pass and both radial and vertical cooling ducts 87 particles displacement in the captured pair of images, liquid 32 were $6 \mathrm{~mm}$ each. It was indicated that 2D CFD predictions 88 velocities within cooling ducts are calculated using the 33 over-estimated plate temperatures whereas 3D CFD 89 software.

34 predictions matched well with temperature measurements. In 35 another study, it was found that higher inlet flow rate and 36 higher inlet oil temperature caused higher deviations from 37 experimental measurements [14].

38 In this paper, an experimental study is carried out to 39 compare the thermal performance between different 40 transformer liquids in terms of liquid flow and temperature 41 distributions in a zig-zag disc type winding model under 42 imitated directed and natural cooling modes. Used 43 experimental setup is introduced in section II. Comparisons of 44 the thermal performances of tested liquids under OD/KD 45 cooling modes are presented in section III. Comparisons of the 46 thermal performances of tested liquids under ON/KN cooling 47 modes are presented in section IV. Discussion and conclusions 48 are given in sections V and VI, respectively.

\section{EXPERIMENTAL DESCRIPTION}

\section{A. Experimental setup}

51 Used experimental setup, as shown in Fig. 1, consists of a 52 disc type winding model, a radiator, a pump and a flow meter. 53 The pump is used to force the liquid to circulate through the 54 system. The winding inlet velocity $\left(V_{i n}\right)$ is measured using a 90

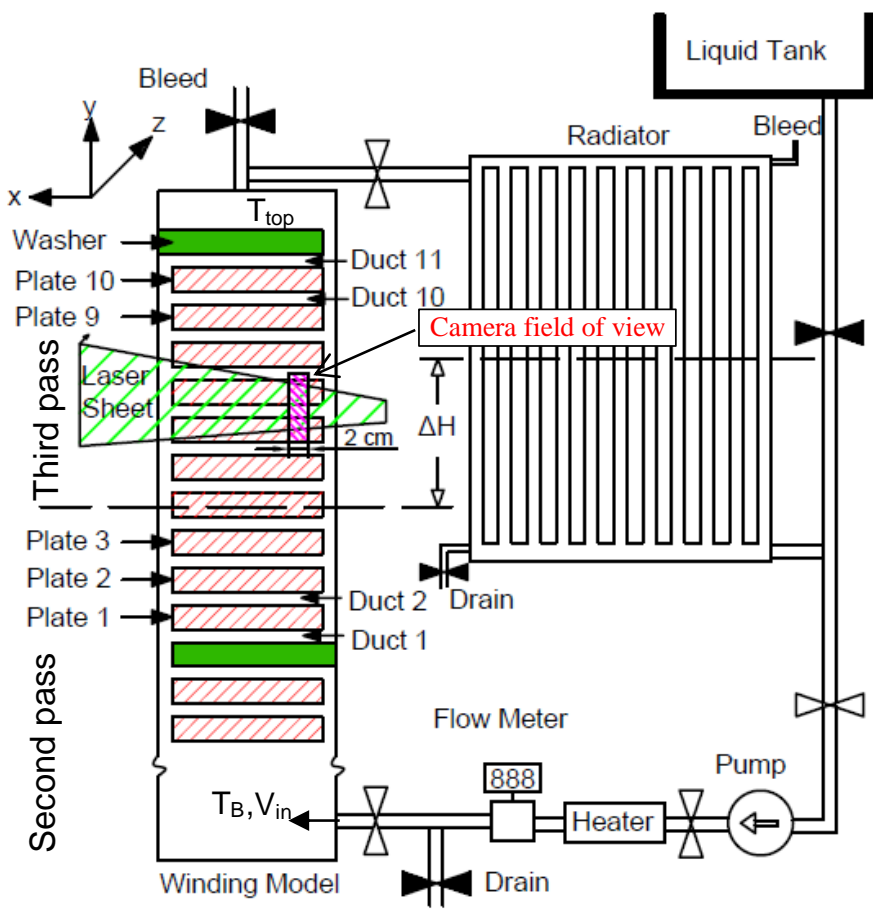
55 positive displacement flow meter with $0.5 \%$ accuracy of 91 Fig. 1.Sketch of experimental setup, the laser sheet was $15 \mathrm{~mm}$ in the z56 reading. A throttling valve is used to set and control $V_{\text {in }}$ as 92 direction away from the wall near the camera 
1 As indicated on Fig. 1, PIV measurements are conducted 46 affect the $R e$ for fixed winding geometry. Higher $v$ causes 2 near the end of a radial cooling duct in the direction of flow 47 lower $R e$ resulting in more uniform liquid flow distribution 3 and the laser sheet was positioned $15 \mathrm{~mm}$ in the z-direction 48 within the winding radial cooling ducts $[4,19]$. The uniformity 4 farther from the winding model wall near the camera. The 49 of liquid flow distribution is indicative to the fair share of flow 5 camera field of view is $2 \mathrm{~cm}$. More detailed descriptions of the 50 rates amongst the pass radial cooling ducts. $v$ is a temperature 6 PIV system and oil flow measurement in radial cooling duct 51 dependent parameter, which is also related to liquid type.

7 are presented in [18].

8 Liquid flow profile within a radial cooling duct is a laminar $52 \mathrm{~A}$

9 profile in typical transformer operating conditions. Using the $53 \quad V_{i n}$

10 PIV system, the maximum velocity $\left(V_{\max }\right)$ of its quasi- 54 To investigate the influence of different liquids on liquid 11 parabolic shape is extracted from the PIV image. The average 55 flow and temperature distributions, experiments were 12 duct velocity $\left(V_{a v}\right)$ is approximately related to $V_{\max }$ using $V_{a v} 56$ conducted under four different $V_{\text {in }}$ of $0.1 \mathrm{~m} / \mathrm{s}, 0.2 \mathrm{~m} / \mathrm{s}, 0.27$ $13=V_{\text {max }} / 1.5$. It was checked that this approximation is $57 \mathrm{~m} / \mathrm{s}$, and $0.3 \mathrm{~m} / \mathrm{s}$. Uniform loss distribution in each plate with 14 acceptable within $10 \%$ comparison accuracy both $58 P_{\text {loss }}=50 \mathrm{~W} / \mathrm{plate}$, which is equivalent to $2010 \mathrm{~W} / \mathrm{m}^{2}$, was 15 experimentally, by comparing summations of volumetric flow 59 applied. $T_{B}$ was fixed to $70{ }^{\circ} \mathrm{C}$.

16 rates in the third pass radial cooling ducts to that measured by 60 Fig. 2 shows liquid flow and temperature distributions in 17 a flow meter at the inlet of the winding model, and by 61 the third pass within the winding model at $V_{\text {in }}$ of $0.1 \mathrm{~m} / \mathrm{s}$. 18 comparing to CFD simulations in our previous publication 62 Liquid flow distributions of MO and GTL are almost identical 19 [19]. The experimental setup and the PIV system were 63 whereas SE caused slightly more uniform flow distribution 20 presented in more detail in $[18,19]$.

\section{B. Liquids under investigations}

64 which means that there is a more fairer share of oil velocities 65 amongst pass radial cooling ducts compared to MO or GTL. A 66 fully uniform flow distribution would indicate that each 22 Three different liquids were used. Firstly, a mineral 67 cooling duct would have the same flow rate.

23 hydrocarbon based transformer oil (MO) [20]. Secondly, a gas 68 The calculated $R e$ of SE is almost half that of the other oils 24 to liquid hydrocarbon based transformer oil (GTL) [21]. The 69 as shown in Table II. Liquid flow distributions for tested 25 third liquid was a synthetic ester based transformer liquid (SE) 70 liquids are relatively uniform which lead to uniform 26 [22]. Table I summarizes the values of key thermal parameters 71 temperature distributions. Temperature profiles of tested 27 of the liquids at three different operating temperatures. The 72 liquids are almost comparable.

28 system is filled with liquid using a liquid tank connected to the 73 Fig. 3 represents liquid flow and temperature distributions 29 experimental setup. Air can leave the experimental setup 74 at $V_{\text {in }}$ of $0.27 \mathrm{~m} / \mathrm{s}$. At this relatively high inlet liquid velocity, 30 through both bleeds above the winding model and the radiator. 75 liquid reverse flow starts to occur in duct 1 for both MO and 31 Before using different liquid, a strict procedure was used to $76 \mathrm{GTL}$. The flow distribution using GTL is almost the same 32 drain the old liquid from the system before testing the next 77 compared to $\mathrm{MO}$ as they have close inlet pass Reynold 33 liquid. Drainage of the old liquid was conducted by 78 numbers. Due to its higher $v$, SE causes more uniform flow 34 dismantling and cleaning the winding model and the pipe 79 distribution and so offers more resistance to liquid reverse 35 work and by flushing the radiator with the new liquid.

\begin{tabular}{|c|c|c|c|c|c|c|}
\hline \multicolumn{2}{|c|}{$\begin{array}{l}\text { Liquid properties at } \\
\text { operating } \\
\text { temperatures }\left({ }^{\circ} \mathrm{C}\right)\end{array}$} & $\begin{array}{c}\sigma \\
\frac{\mathrm{kg}}{\mathrm{m}^{3}}\end{array}$ & $\begin{array}{c}v \\
\frac{m m^{2}}{s}\end{array}$ & $\begin{array}{c}k_{c} \\
W \\
m \cdot K\end{array}$ & $\begin{array}{l}C_{p} \\
\frac{J}{k g . K}\end{array}$ & $\begin{array}{l}\beta_{T h} \\
\frac{1}{K}\end{array}$ \\
\hline \multirow{3}{*}{$\begin{array}{l}\text { Mineral oil } \\
\text { (MO) }\end{array}$} & 40 & 858 & 9.2 & 0.132 & 1794 & $\mathrm{~N} / \mathrm{A}$ \\
\hline & 60 & 845 & 5.2 & 0.130 & 1877 & 0.00078 \\
\hline & 80 & 832 & 3.4 & 0.128 & 1956 & $\mathrm{~N} / \mathrm{A}$ \\
\hline \multirow{3}{*}{$\begin{array}{l}\text { Gas-to- } \\
\text { liquid } \\
\text { (GTL) }\end{array}$} & 40 & 793 & 9.6 & 0.142 & 2271 & 0.00081 \\
\hline & 60 & 780 & 5.6 & 0.140 & 2365 & 0.00081 \\
\hline & 80 & 767 & 3.7 & 0.138 & 2458 & 0.00084 \\
\hline \multirow{3}{*}{$\begin{array}{l}\text { Synthetic } \\
\text { ester } \\
\text { (SE) }\end{array}$} & 40 & 956 & 28 & 0.143 & 1933 & 0.00077 \\
\hline & 60 & 941 & 14 & 0.141 & 1994 & 0.00078 \\
\hline & 80 & 926 & 8 & 0.139 & 2023 & 0.00079 \\
\hline
\end{tabular}

\section{III. COMPARISON UNDER DIRECTED COOLING MODES}

39 Under OD/KD cooling modes, liquid is forced to circulate 40 within the winding using a pump. Washers within the winding 41 structure force the liquid to flow in a zig-zag fashion. 42 According to $[4,19]$, liquid flow distribution is influenced by 43 dimensionless numbers such as the $R e$ number and 44 geometrical based dimensionless numbers $\alpha, \beta$, and $\gamma$ [4]. 45 Since the $R e$ is defined as $R e=\left(D_{h} \times V_{i n}\right) / v$, only $v$ and $V_{\text {in }}$
80 flow phenomenon. Compared to the previous test under $V_{\text {in }}$ of $810.1 \mathrm{~m} / \mathrm{s}$, liquid flow distributions are less uniform which 82 directly cause less uniform temperature profiles. The 83 occurrence of liquid reverse flow causes higher $H S T_{\text {rise }}$ for 84 both MO and GTL compared to SE.

85 TABLE II

86 TESTS SUMMARY UNDER DIRECTED COOLING MODE WITH $T_{B}=70^{\circ} \mathrm{C}$

\begin{tabular}{|c|c|c|c|c|c|c|}
\hline $\begin{array}{c}V_{\text {in }} \\
{[\mathrm{m} / \mathrm{s}]}\end{array}$ & Liquid Type & $\begin{array}{c}T_{\text {top }} \\
{[\mathrm{K}]}\end{array}$ & $R e^{*}$ & $\begin{array}{c}H S T_{\text {rise }} \\
{[\mathrm{K}]}\end{array}$ & $\begin{array}{c}H S T \\
\text { location }\end{array}$ & $\begin{array}{c}\text { Reverse } \\
\text { flow }\end{array}$ \\
\hline \multirow{3}{*}{0.1} & MO & 78.6 & 443 & 17.5 & Plate 4 & No \\
\cline { 2 - 7 } & GTL & 78.1 & 387 & 17.9 & Plate 4 & No \\
\cline { 2 - 7 } & SE & 76.7 & 173 & 18.6 & Plate 3 & No \\
\hline \multirow{3}{*}{0.2} & MO & 74.7 & 887 & 14.3 & Plate 1 & No \\
\cline { 2 - 7 } & GTL & 74.6 & 774 & 15.3 & Plate 1 & No \\
\cline { 2 - 7 } & SE & 71.8 & 346 & 13.4 & Plate 1 & No \\
\hline \multirow{3}{*}{0.27} & MO & 73.7 & 1183 & 17.6 & Plate 1 & Yes \\
\cline { 2 - 7 } & GTL & 73.8 & 1032 & 17.2 & Plate 1 & Yes \\
\cline { 2 - 7 } & SE & 74.1 & 461 & 12.4 & Plate 1 & No \\
\hline \multirow{3}{*}{0.3} & MO & 73.8 & 1330 & 15.9 & Plate 1 & Yes \\
\cline { 2 - 7 } & GTL & 73.5 & 1161 & 16.6 & Plate 1 & Yes \\
\cline { 2 - 7 } & SE & 73.4 & 520 & 12.3 & Plate 1 & No \\
\hline
\end{tabular}

$87 * R e$ was calculated using $v$ at $T_{B}=70^{\circ} \mathrm{C}$ and $D_{h}=0.018 \mathrm{~m}$ 

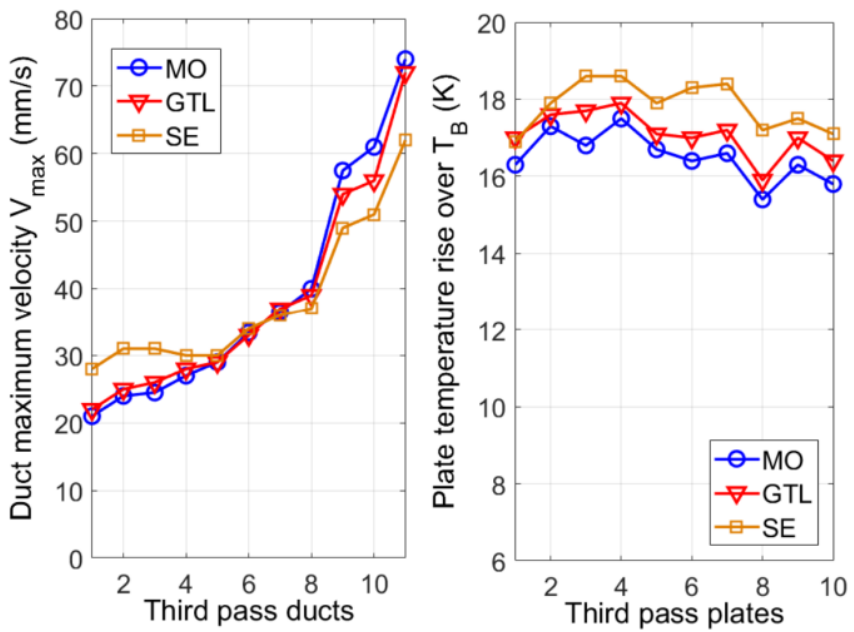

2 Fig. 2 Liquid flow and temperature distributions under directed cooling modes 3 with $\mathrm{V}_{\text {in }}=0.1 \mathrm{~m} / \mathrm{s}, \mathrm{P}_{\text {loss }}=2010 \mathrm{~W} / \mathrm{m}^{2}$, and $\mathrm{T}_{\mathrm{B}}=70^{\circ} \mathrm{C}$.
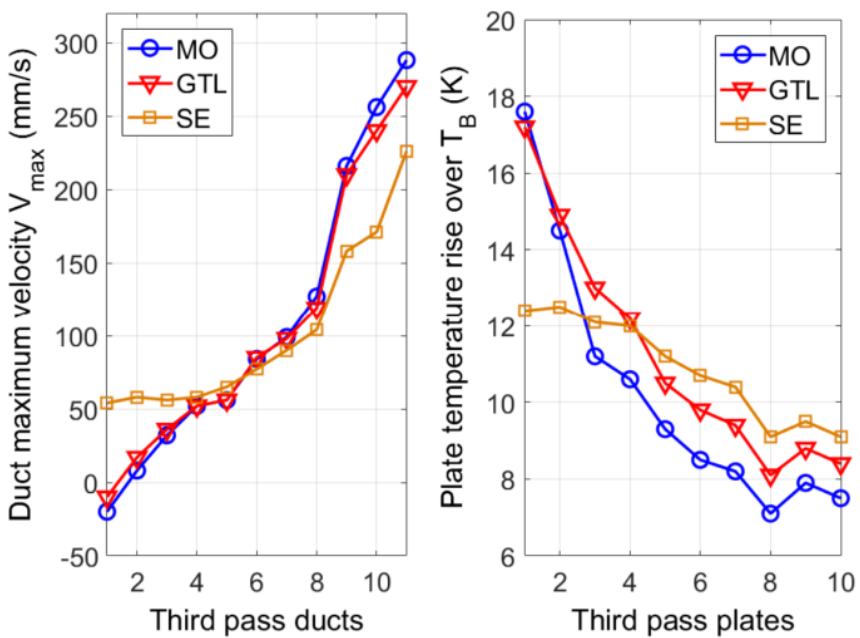

5 Fig. 3. Liquid flow and temperature distributions under directed cooling 6 modes with $\mathrm{V}_{\text {in }}=0.27 \mathrm{~m} / \mathrm{s}, \mathrm{P}_{\text {loss }}=2010 \mathrm{~W} / \mathrm{m}^{2}$, and $\mathrm{T}_{\mathrm{B}}=70^{\circ} \mathrm{C}$.

8 B. Pressure loss under isothermal conditions with uniform

$9 \quad$ liquid temperature $=70^{\circ} \mathrm{C}$

10 At a fixed winding geometry and $V_{\text {in }}$, higher viscosity liquid 11 would lead to higher pressure losses in the winding. Under 12 isothermal testing conditions with uniform liquid temperature 13 of $70^{\circ} \mathrm{C}, P_{L}$ was measured under a range of $V_{\text {in }}$ from $0.05 \mathrm{~m} / \mathrm{s}$ 14 to $0.35 \mathrm{~m} / \mathrm{s}$ for the three different liquids as shown in Fig. 4 . 15 Pressure measurement ports were fixed on the centre line of 16 the first pass inlet washer and the centre line of the third pass 58 17 outlet washer.

$18 \mathrm{MO}$ and GTL cause comparable pressure loss over the 19 winding model. SE causes higher pressure loss over the 20 winding model compared to the other two liquids.

21 To summarize, three main observations are being made. 22 First, with higher $V_{i n}$, liquid flow distribution in the third pass 23 radial cooling ducts is less uniform for all liquids and this 24 directly results in less uniform temperature profiles. Less 25 uniform reflects that more liquid flows in top radial cooling 26 ducts compared to bottom cooling ducts which cause higher 27 temperatures in bottom plates. Second, MO and GTL showed 28 similar liquid flow and temperature distributions whereas SE 29 caused more uniform liquid flow and temperature
30 distributions. Hence, SE offered higher resistance to the 31 occurrence of liquid reverse flow. Third, assuming a 32 retrofilling scenario with the same pump and so fixed pressure 33 loss over the winding of $300 \mathrm{~Pa}$ as shown in Fig. 4, SE would 34 cause lower $V_{\text {in }}$ close to $0.22 \mathrm{~m} / \mathrm{s}$ compared to the two other 35 liquids which would cause $V_{\text {in }}$ close to $0.27 \mathrm{~m} / \mathrm{s}$. Lower $V_{i n}$, 36 and higher $v$, indicate lower $R e$. Lower $R e$ leads to more 37 uniform flow distributions within the winding passes [4, 19]. 38 With lower $R e$, liquid reverse flow is less likely to occur 39 under SE. Under $V_{\text {in }}=0.27 \mathrm{~m} / \mathrm{s}$, liquid reverse flow occurred 40 under MO and GTL and it did not occur under SE and so the 41 HST was lower when using SE.

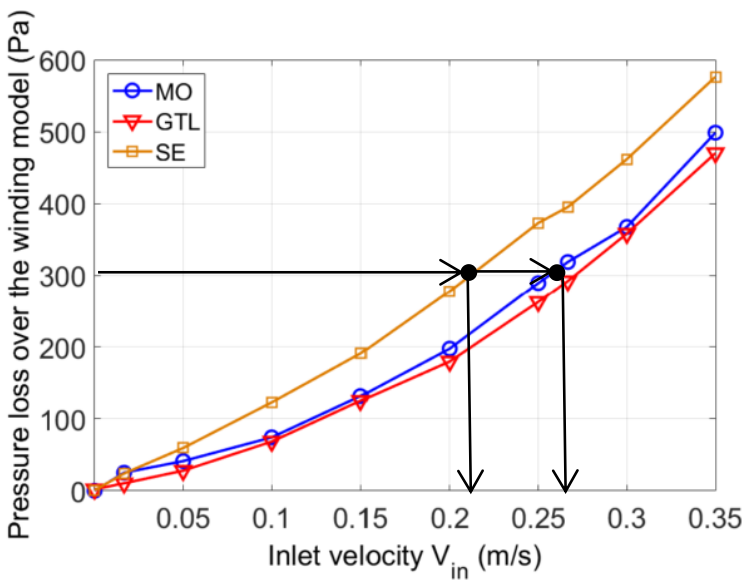

43 Fig. 4. Measured $\mathrm{P}_{\mathrm{L}}$ over the winding model under isothermal conditions with 44 uniform liquid temperature $=70^{\circ} \mathrm{C}$.

\section{COMPARISON UNDER NATURAL COOLING MODES}

Under $\mathrm{ON} / \mathrm{KN}$ cooling modes, the flow is driven by the 47 developed thermosyphon force $\left(p_{T h}\right)$ within the transformer 48 hydraulic cooling loop. At steady state, $V_{\text {in }}$ is reached when $49 p_{T h}$ is equal to the total pressure loss in the hydraulic loop [6]. 50 According to [6], $p_{T h}$ can be calculated using (1). $\Delta T$ can be 51 related to the total electric losses in the winding $\left(P_{\text {loss,total }}\right)$ 52 and to the inlet mass flow rate $(\dot{m})$ as presented in (2). $\dot{m}$ is 53 related to $V_{\text {in }}$ using $\sigma$ and $A_{c}$ as shown in (3). $P_{L}$ can be 54 calculated by adding all pressure drops around the hydraulic 55 loop. Darcy - Weisback equation shown in (4) can be used for 56 evaluation of pressure drops within individual sections of the 57 winding model and transformer loop [6, 23, 24].

$$
p_{T h}=g \sigma_{o} \beta_{T h} \Delta T \Delta H
$$

where $\sigma_{o}$ is the liquid density at a reference temperature, $59 \beta_{T h}$ is the liquid thermal expansion coefficient, $g$ is the 60 acceleration of gravity, $\Delta H$ is the height difference between 61 radiator and winding centres, and $\Delta T$ is the increase in liquid 62 temperature across the winding as defined in (2).

$$
\begin{aligned}
& \Delta T=\frac{P_{\text {loss }, \text { total }}}{\dot{m} \times C_{p}} \\
& \dot{m}=\sigma \times A_{c} \times V_{\text {in }} \\
& P_{L, i}=f_{i} \times \frac{L_{i}}{D_{h, i}} \times \sigma \times \frac{V_{i n, i}^{2}}{2}
\end{aligned}
$$

63 where $f_{i}$ is the friction coefficient, $L_{i}$ is the equivalent duct 64 length, and the $i$ subscript refers to the $i$ component in the 
1 hydraulic loop

$$
R_{i}=G_{r} / R e^{2}
$$

2 In the following analysis, a global view of the hydraulic 50 3 loop of the experimental setup is considered in which the 51 mean liquid temperature.

4 entire hydraulic loop is lumped and modelled with an 52 In the following, performances of different liquids are 5 equivalent pipe in order to relate liquid only parameters, such 53 compared under two different approaches. The first approach, 6 as viscosity, density, and thermal expansion coefficient, to the 54 section $\mathrm{A}$, is designed to run experiments under fixed $\mathrm{V}_{\text {in. }}$. The 7 inlet velocity developed naturally by the systems' 55 second approach is to compare MO and SE under a more 8 thermosyphon induced pressure. This approach does not look 56 realistic scenario in which the system determines $V_{\text {in }}$ based on 9 into detailed modelling of pressure losses internal to the 57 equation 6

10 winding model ducts and joints. For this detailed modelling of

11 pressure losses, readers can refer to published work related to 58 A. Flow and temperature distributions under different $V_{\text {in }}$ 12 network modelling [24-29]. Network models are less accurate 59 Tests were conducted with three different $V_{\text {in }}$ of $0.026 \mathrm{~m} / \mathrm{s}$, 13 but they demand less computational resources compared to $600.021 \mathrm{~m} / \mathrm{s}$, and $0.017 \mathrm{~m} / \mathrm{s}$ which are within the expected range 14 CFD simulations. As such, they are used by designers in early 61 of ON/KN transformers [7]. Table III represents key test 15 stages during the transformer design iteration process.

62 results with the calculated $R_{i}$ number for each test. It is 16 Assuming that at a specific steady state operating point, the 63 observed that lower $V_{\text {in }}$ causes less uniform liquid flow and 17 experimental setup hydraulic loop can be modelled as an 64 temperature distributions, i.e. more dominated natural cooling 18 equivalent pipe with an equivalent length $L_{e q}$ and an 65 regimes, which are reflected in higher $R_{i}$ numbers. In general 19 equivalent hydraulic diameter $D_{h, e q}$ such that the flow is 66 under ON/KN cooling modes, more liquid flows into pass 20 laminar. Laminar flow is a reasonable assumption for $\mathrm{ON} / \mathrm{KN} 67$ bottom cooling ducts and less liquid flows into pass top 21 cooling modes. Also, assume that average inlet liquid flow 68 cooling ducts [8]. Individual tests are discussed as follows. 22 velocity equals to $V_{i n}$ and pressure drop over the pipe equals 69 Fig. 5 shows recorded liquid flow and temperature 23 to $P_{L}$.

70 distributions at steady state for tests under $V_{\text {in }}$ of $0.026 \mathrm{~m} / \mathrm{s}$. 24 In this case, the equivalent friction coefficient $f_{e q}$ can be 71 Liquid flow and temperature distributions follow almost an 25 presented by (5). To relate $V_{\text {in }}$ to liquid only dependent 72 opposite trend to that under OD/KD cooling modes. MO and 26 properties, first, (3) is substituted in (2) and the resulting (2) is 73 GTL have almost the same liquid flow distributions whereas 27 substituted in (1). Then, (5) is substituted in (4). By equating 74 SE has relatively more uniform flow distribution contributing 28 resulting (1) and (4), i.e. $p_{T h}=P_{L}$, (6) is produced. The first 75 to higher flow rates into pass top cooling ducts. For both MO 29 term in (6) is related to the winding model geometries and to 76 and GTL, oil stagnation was observed in duct 11 but it did not 30 the total power losses whereas the second term is related to 77 occur for SE. Occurrence of oil stagnation under natural 31 only liquid properties. In the current experimental setup, (6) 78 cooling was also reported using CFD simulations in [31, 32]. 32 can be used approximately to answer the question as what 79 Therefore, SE has lower $H S T_{\text {rise }}$ compared to the other 33 would be the new $V_{i n}$ if using a new liquid in the winding 80 liquids. Using SE, it can be observed that the Re number is 34 model under the same winding model power losses and 81 almost half of the other liquids and the $R_{i}$ number is slightly 35 geometrical conditions compared to the old liquid case to 82 lower.

36 reflect a retrofilling scenario.

$$
f_{e q}=\frac{C}{R e}=\frac{C \times v}{D_{h, e q} \times V_{i n}}
$$

37 where $C$ is a constant which depends on the flow regime 38 and the pipe shape

$$
V_{\text {in }}^{2}=\left\{\frac{2 g \times D_{h, e q}^{2} \times \Delta H \times P_{\text {loss }, \text { total }}}{C \times A_{c} \times L_{e q}}\right\} \times\left\{\frac{\beta_{T h}}{v \times C_{p} \times \sigma}\right\}
$$

39 In tests conducted henceforth, $P_{\text {loss }}$ is fixed to $30 \mathrm{~W} /$ plate 40 which is equivalent to $1200 \mathrm{~W} / \mathrm{m}^{2} . T_{B}$ is maintained at $60^{\circ} \mathrm{C}$. $41 V_{\text {in }}$ is still controlled by external pump and valve. To check 93 42 whether the testing conditions can represent natural cooling 94 43 regime within the winding model, Richardson number $\left(R_{i}\right)$ is 960 44 calculated for all conducted tests. $R_{i}$ is presented in $(8)$ and ${ }^{97}$ 45 defined as the ratio of Grashof number $\left(G_{r}\right)$, shown in (7), to 46 the $R e$ number square. According to [30], if $R_{i}<<1$, then the 47 cooling regime is considered $\mathrm{OD} / \mathrm{KD}$ dominated regime. If $48 R_{i}>>1$, then the cooling regime is considered $\mathrm{ON} / \mathrm{KN}$ 49 dominated regime.

$$
G_{r}=\frac{g \beta_{T h} D_{h}^{3}}{v^{2}} \times\left(T_{m w}-T_{m o}\right)
$$

83 Results under $V_{\text {in }}$ of $0.021 \mathrm{~m} / \mathrm{s}$ are shown in Fig. 6. Liquid 84 stagnation occurs in duct 10 under both MO and GTL whereas 85 it did not occur when testing under SE. Liquid stagnation 86 causes a large increase in temperature of nearby plate; in this 87 case it is plate 9. Liquid flow distribution was almost identical 88 when testing using MO and GTL and it was more uniform 89 when testing with SE. As a result of liquid stagnation not 90 occurring under SE, $H S T_{\text {rise }}$ was lower compared to the other 91 liquids. In comparison to tests under $V_{\text {in }}$ of $0.026 \mathrm{~m} / \mathrm{s}$, higher $92 R_{i}$ numbers are observed which indicate more dominating $93 \mathrm{ON} / \mathrm{KN}$ regimes.

94

SUMMARY OF TEST RESULTS UNDER ON/KN COOLING MODE WITH CALCULATED DIMENSIONLESS PARAMETERS. TESTS WERE CONDUCTED UNDER

\begin{tabular}{|c|c|c|c|c|c|c|}
\hline Liquid Type* & $\begin{array}{c}T_{\text {top }} \\
{\left[{ }^{\circ} \mathrm{C}\right]}\end{array}$ & $\begin{array}{c}T_{m w} \\
{\left[{ }^{\circ} \mathrm{C}\right]}\end{array}$ & $\begin{array}{c}H S T_{\text {rise }} \\
{[\mathrm{K}]}\end{array}$ & $R e^{*}$ & $G_{r}{ }^{*}$ & $R_{i}$ \\
\hline \multicolumn{7}{|c|}{ Tests conducted under $\mathrm{V}_{\text {in }}=0.026 \mathrm{~m} / \mathrm{s}$} \\
\hline $\mathrm{MO}$ & 80.4 & 80.3 & 36.5 & 117 & 28436 & 2.1 \\
\hline $\mathrm{GTL}$ & 76.6 & 77.5 & 33.6 & 102 & 20435 & 2 \\
\hline $\mathrm{SE}$ & 77.3 & 78.3 & 25.8 & 46 & 3939 & 1.9 \\
\hline $\mathrm{MO}$ & 83.7 & 85 & 49.2 & 97.7 & 36968 & 3.9 \\
\hline $\mathrm{GTL}$ & 80.6 & 82.9 & 47.5 & 85 & 26645 & 3.7 \\
\hline
\end{tabular}




\begin{tabular}{|c|c|c|c|c|c|c|}
\hline SE & 81.2 & 80.4 & 36.5 & 38.2 & 3919 & 2.7 \\
\hline Tests conducted under $\mathrm{V}_{\text {in }}=0.017 \mathrm{~m} / \mathrm{s}$ \\
\hline MO & 87.7 & 89.8 & 54 & 78.2 & 44584 & 7.3 \\
\hline GTL & 82.6 & 86.1 & 54 & 68.2 & 32396 & 7 \\
\hline SE & 83.5 & 85.2 & 52 & 30.5 & 5450 & 5.8 \\
\hline
\end{tabular}

$1 * R e$ and $G_{r}$ were calculated using $v$ at $T_{B}=70{ }^{\circ} \mathrm{C}$ and $D_{h}=0.018 \mathrm{~m}$

2 Results under $V_{\text {in }}$ of $0.017 \mathrm{~m} / \mathrm{s}$ are shown in Fig 7. With 3 lower $V_{i n}$, more dominating natural cooling regime is 4 produced with higher $R_{i}$ numbers. Similar to previous tests, $5 \mathrm{MO}$ and GTL gave almost identical flow distributions. Liquid 6 reverse flow occurred under both MO and GTL, in duct 8 and 7 duct 9, whereas liquid stagnation occurred under SE in duct 8 10. It was observed that higher viscosity liquids delay the 9 occurrence of oil stagnation top of the pass under natural 10 cooling modes. Because of the occurrence of liquid reverse 11 flow and liquid stagnation, the differences in the $H S T_{\text {rise }}$ 12 between the liquids were minimum amongst the conducted 13 tests in this section.
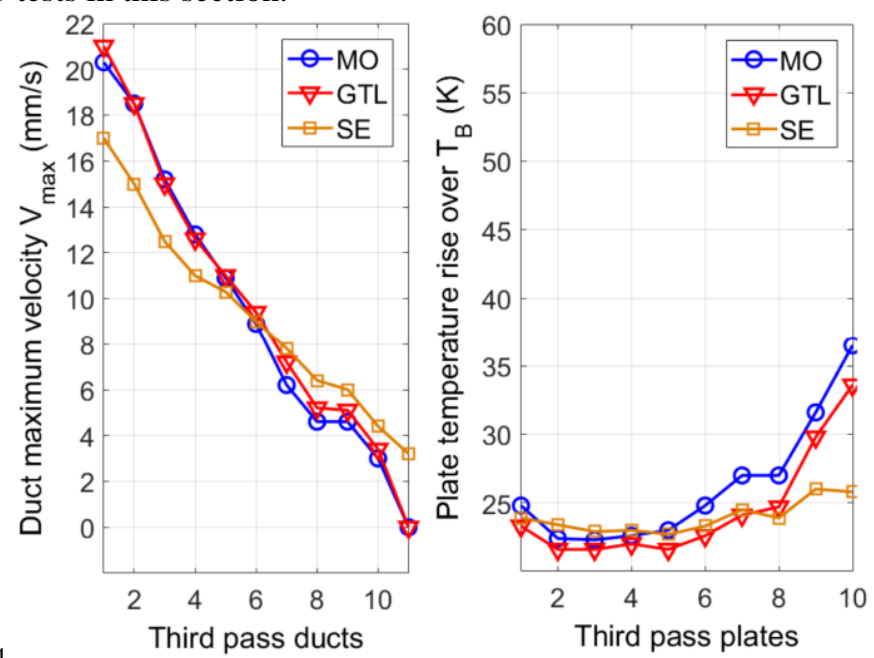

15 Fig. 5. Liquid flow and temperature distributions under $\mathrm{ON} / \mathrm{KN}$ cooling mode 16 with $\mathrm{V}_{\text {in }}=0.026$ and $\mathrm{T}_{\mathrm{B}}=60^{\circ} \mathrm{C}$.

17
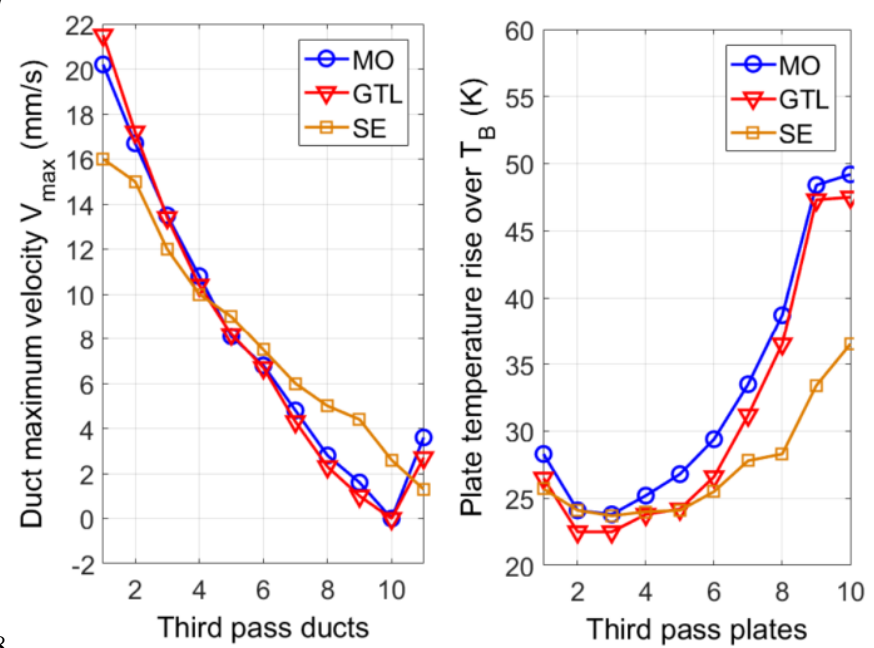

19 Fig. 6. Liquid flow and temperature distributions under $\mathrm{ON} / \mathrm{KN}$ cooling 20 modes with $\mathrm{V}_{\text {in }}=0.021 \mathrm{~m} / \mathrm{s}$ and $\mathrm{T}_{\mathrm{B}}=60^{\circ} \mathrm{C}$.

21

22 B. Comparison of $M O$ and SE under a specific retrofilling 23 scenario
24 In the previous section, the performances of different 25 liquids were compared under fixed $V_{\text {in }}$ which is not reflective 26 to actual transformer retrofilling condition. However, as 27 demonstrated in (6) the liquid properties influence the 28 developed $V_{\text {in }}$ under ON/KN cooling modes.
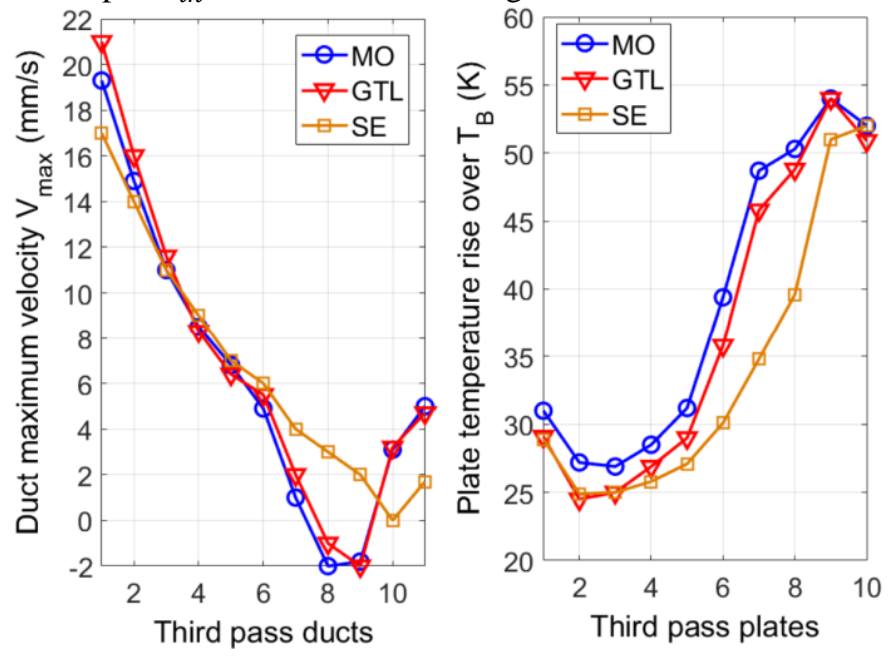

30 Fig. 7. Liquid flow and temperature distributions under $\mathrm{ON} / \mathrm{KN}$ cooling 31 modes with $V_{\text {in }}=0.017 \mathrm{~m} / \mathrm{s}$ and $\mathrm{T}_{\mathrm{B}}=60^{\circ} \mathrm{C}$.

32 It was reported in literature that when retrofilling a power 33 transformer with a new liquid, in point of view of thermal 34 aspects, careful considerations need to be made since the HST 35 may be increased [9-11]. The main reason for the increase in 36 the HST is the reduction of the developed $V_{\text {in }}$ when using a 37 different liquid which has higher viscosity. Under the present 38 experimental setup, $V_{\text {in }}$ is controlled instead of allowing the 39 system to determine its value similar to what was conducted in 40 [17]. For this reason, (6) can be used, though requires further 41 verifications, to approximately answer the question as of what 42 would be the naturally developed $V_{\text {in }}$ when using a new liquid 43 under the same winding model geometries and operating 44 conditions, presented in the first term in (6), so that different 45 liquids performances are judged fairly. As an example, a 46 specific case study is discussed in which SE is compared to $47 \mathrm{MO}$ in a hypothetical retrofilling scenario. According to (6) 48 and the liquids information shown in Table I at temperature 70 $49^{\circ} \mathrm{C}$, MO would have an inlet velocity $\left(V_{i n, M O}\right)$ of 1.69 times 50 higher than that of $\mathrm{SE}\left(V_{i n, S E}\right)$, i.e. $V_{i n, M O}=1.69 \times V_{i n, S E}$. It is 51 very important to emphasize here that this relationship is only 52 valid for the related testing conditions and the studied winding 53 arrangements. Further experimental validations are required to 54 justify the validity of (6) in a broader context.

55 Tests were conducted under uniform losses of $P_{\text {loss }}=30$ $56 \mathrm{~W} /$ plate or equivalently $1200 \mathrm{~W} / \mathrm{m}^{2} . T_{B}$ was maintained at 60 $57^{\circ} \mathrm{C}$. The winding model geometries are relatively close to the 58 specified low voltage winding of a $22 \mathrm{kV}, 250$ MVA 59 transformers mentioned in [25]. Table IV provides a summary 60 of key test results in which $V_{i n, M O}=0.028 \mathrm{~m} / \mathrm{s}$ and $V_{i n, S E}=$ $610.017 \mathrm{~m} / \mathrm{s}$. Test results are presented in Fig. 8. A difference in 62 the $H S T_{\text {rise }}$ between MO and SE of $26{ }^{\circ} \mathrm{C}$ was recorded while 63 only $6{ }^{\circ} \mathrm{C}$ difference in $T_{\text {top }}$ was recorded between the two 64 liquids. Though this case may be the worst case possible of a 65 bad retrofilling choice for $\mathrm{ON} / \mathrm{KN}$ transformer, it is intended 
1 to raise the awareness that appropriate consideration and 38 pass top cooling ducts. To compare the liquids' thermal 2 selection of good transformer candidates is important to fully 39 performances fairly, (6) was used to roughly estimate as of 3 benefit from the advantages provided by alternative liquids. 40 what would be the new $V_{\text {in }}$ when using a new liquid compared 4 The increase in the HST under SE, in this studied case, is 41 to the old one. The reported data of measured inlet and outlet 5 because liquid stagnation occurs in duct 10 and that liquid 42 liquid temperatures under similar transformer loading levels 6 flow distribution under MO is much more uniform compared 43 indicate that mineral oils have a near 1.6 higher $\dot{m}$ compared 7 to SE. This can show that the proper selection of the candidate 44 to natural ester $[9,11]$ which supports the estimated 8 for retrofilling of any transformers is really important. It is 45 relationship between $V_{\text {in,Mo }}$ and $V_{i n, S E}$ using (6), though 9 expected, based on the previous tests, that GTL would perform 46 experimental validation of (6) is still required before further 10 similar to MO under the current experimental setup 47 expansion of conclusions. Ester based liquid was compared to 11 geometries and testing conditions. 48 mineral oil, using (6), in a retrofilling scenario and it was

12 TABLE IV

13 TEST UNDER RETROFILLING SCENARIO WITH T $\mathrm{T}_{\mathrm{B}}$ FIXED AT $60^{\circ} \mathrm{C}$

\begin{tabular}{|c|c|c|c|c|c|c|c|}
\hline $\begin{array}{c}\text { Liquid } \\
\text { Type* }\end{array}$ & $\begin{array}{c}V_{\text {in }} \\
{[\mathrm{m} / \mathrm{s}]}\end{array}$ & $\begin{array}{c}T_{\text {top }} \\
{\left[{ }^{\circ} \mathrm{C}\right]}\end{array}$ & $\begin{array}{c}T_{m w} \\
{\left[{ }^{\circ} \mathrm{C}\right]}\end{array}$ & $\begin{array}{c}H S T_{\text {rise }} \\
{[\mathrm{K}]}\end{array}$ & $R e^{*}$ & $G_{r}{ }^{*}$ & $R_{i}$ \\
\hline $\mathrm{MO}$ & 0.028 & 77 & 78 & 26 & 125 & 25544 & 1.6 \\
\hline $\mathrm{SE}$ & 0.017 & 83.5 & 85.2 & 52 & 30.5 & 5450 & 5.8 \\
\hline
\end{tabular}

$14 * R e$ and $G_{r}$ were calculated using $v$ at $T_{B}=70^{\circ} \mathrm{C}$ and $D_{h}=0.018 \mathrm{~m}$
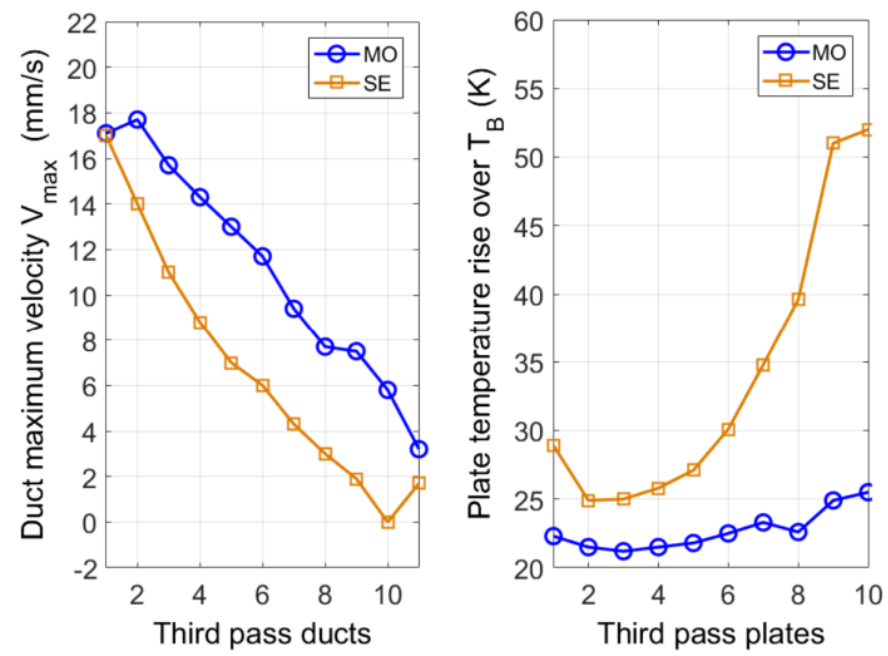

16 Fig. 8. A comparison between the thermal performance of MO and SE under a 17 specific retrofilling scenario in which according to (6), which required 18 experimental validations, MO develops 1.69 higher flow rate compared to SE.

\section{DISCUSSIONS}

20 Under directed cooling modes, it was predicted that 21 dimensionless numbers, such as the $R e$ number and the ratio 22 between the radial to the axial cooling ducts $(\alpha)$, influence 77 23 liquid flow distribution in a pass [4]. The $R e$ number is a 24 function of $V_{\text {in }}$ and $v$. Higher $v$, or lower $V_{\text {in }}$, leads to a lower 78 $25 R e$ and hence a more uniform flow distribution. Ester based 79 Materials, National Grid, Scottish Power, Shell Global 26 liquids have higher viscosities compared to mineral and gas- 80 Solutions (UK), TJ|H2b Analytical Services, UK Power 27 to-liquid oils and so they develop a more uniform flow 81 Networks and Weidmann Electrical Technology for their 28 distribution within the winding passes. Higher viscous liquids 82 financial and technical contributions to the Transformer 29 provide more resistance to the occurrence of liquid reverse 83 Research Consortium at The University of Manchester.

30 flow in pass bottom cooling ducts. Nonetheless, the ester 31 liquid causes higher pressure loss within the winding and so 84 32 for the same pump, lower $V_{\text {in }}$ develops and so even more 85 33 uniform liquid flow distribution is produced.

34 Under natural cooling modes and for the zig-zag disc type 87 35 winding model, results showed that the difference in the HST 88 36 between different liquids is relatively small when liquid 99 37 reverse flow, or liquid stagnation, occurs under all liquids in 91 49 observed that the differences in the $H S T_{\text {rise }}$ and in $T_{\text {top }}$ 50 between the two oils are consistent with reported 51 measurements in the literature under actual retrofilling tests 52 [11] for zig-zag disc type power transformers. Results 53 facilitate that the difference in $T_{\text {top }}$ may not be a good 54 indicator of the difference in the $H S T_{\text {rise }}$. Ester based liquid 55 may increase the HST due to its higher viscosity which causes 56 lower $V_{i n}$ to develop. Still, in the industry the measurement of 57 top liquid temperature could be carried out easier.

\section{8}

\section{CONCLUSION}

59 Experimental investigation and comparison of the thermal 60 performance of different transformer liquids were conducted 61 under both $\mathrm{OD} / \mathrm{KD}$ and $\mathrm{ON} / \mathrm{KN}$ cooling modes. A disc type 62 zig-zag winding model was used and inlet liquid velocity was 63 controlled and set to desired values. Three liquids were 64 compared which are a mineral hydrocarbon based transformer 65 oil (MO), a gas to liquid hydrocarbon based transformer oil 66 (GTL), and a synthetic ester based transformer liquid (SE). 67 Under both OD/KD and ON/KN cooling modes, MO and GTL 68 gave similar liquid flow distributions within the winding 69 model and very close temperature profiles. Under OD/KD 70 cooling modes, SE showed more resistance to the liquid 1 reverse flow phenomenon and gave more uniform liquid flow 2 distribution. Nonetheless, SE caused higher pressure losses 73 within the winding model. Under $\mathrm{ON} / \mathrm{KN}$ cooling modes and 74 in a retrofilling perspective, SE increased the HST compared 75 to MO under the conducted testing conditions and winding 6 model geometries.

\section{ACKNOWLEDGMENT}

The authors would like to express their gratitude to M\&I 
in Int. Conf. on Condition Monitoring and Diagnosis (CMD), pp. 76 $52-55,2016$

[3] J. Zhang, X. Li, "Oil cooling for disk-type transformer winding- 78 part I: theory and model development," IEEE Tran. Power Del., 79 vol. 21, pp. 1318-1325, 2006

[4] X. Zhang, Z.D. Wang, Q. Liu, "Prediction of Pressure Drop and 81 Flow Distribution in Disc Type Transformer Windings in an OD 82 Cooling Mode," IEEE Tran. Power Del., vol. 32, pp. 1655-1664, 83 2017

[5] M. Nakadate, K. Toda, K. Sato, D. Biswas, C. Nakagawa, T. 85 Yanari, "Gas cooling performance in disc winding of large- 86 capacity gas-insulated transformers," IEEE. Trans. Power. Del., 87 vol. 11, no. 2, pp. 903-908, 1996

[6] M. Yamaguchi, T. Kumasaka, Y. Inui, S. Ono, "The Flow Rate in 89 a Self-Cooled Transformers," IEEE Trans. Power Apparatus and 90 Syst. vol. PAS-100, pp. 956-963, 1981

77] J. Zhang, X. Li, "Coolant flow distribution and pressure loss in 92 ONAN transformer winding part II: optimization of design 93 parameters," IEEE Trans. Power Del., vol. 19, pp. 194-199, 200494

[8] F. Torriano, M. Chaaban, P. Picher, "Numerical study of 95 parameters affecting the temperature distribution in a disc-type 96 transformer winding," Appl. Therm. Eng., vol. 30, pp. 2034-2044, 97 2010

[9] R. Girgis, M. Bernesjö, G.K. Frimpong, "Detailed performance of 99 a 50 MVA transformer filled with a natural ester oil versus mineral100 oil," in CIGRE 2010, A2_107_2010, Paris

[10] J. Hajek, J. Kranenborg, P. Sundqvist, et al., "Considerations for102 the Design, Manufacture, and Retro-filling of Power Transformers103 with High Fire Point, Biodegradable Ester Fluids," Proc. CIGRE104 Gen. Session, A2_203, 2012

[11] K. Dongjin, K. Kyosun, W. Jungwook, K. Yungsig, "Hot spot106 temperature for $154 \mathrm{kV}$ transformer filled with mineral oil and107 natural ester fluid," IEEE Trans. Diel. Elect. Ins., vol. 19, pp.108 1013-1020, 2012

12] F. Torriano, H. Campelo, M. Quintela, P. Labbé, and P. Picher, "Numerical and experimental thermofluid investigation of different disc-type power transformer winding arrangements," International Journal of Heat and Fluid Flow, vol. 69, pp. 62-72, 2018

13] S. Tenbohlen, N. Schmidt, C. Breuer, S. Khandan, and R. Lebreton, "Investigation of Thermal Behavior of an Oil-Directed Cooled Transformer Winding," IEEE Tran. Power Del., vol. 33, pp. 1091-1098, 2018.

14] N. Schmidt, S. Tenbohlen, S. Chen, and C. Breuer, "Numerical and experimental investigation of the temperature distribution inside oil-cooled transformer windings," in 18th International Symposium on High Voltage Engineering, p. 25, 2013.

[15] P. Allen, O. Szpiro, E. Campero, "Thermal analysis of power transformer windings," Electric Manchines and Electromagnetics, vol. 6,1981

[16] J-M. Mufuta, "Comparison of experimenttal values and numerical simulation on a set-up simulating the cross-section of a disc-type transformer," Int. Jour. Therm. Sciences, vol. 38, pp. 424-435, 1999

17] J. Zhang, X. Li, M. Vance, "Experiments and modeling of heat transfer in oil transformer winding with zigzag cooling ducts," Appl. Therm. Eng., vol. 28, pp. 36-48, 2008

[18] M. Daghrah, Z.D. Wang, Q. Liu, Ch. Krause, P.W.R. Smith, "Characterization of Oil Flow within Radial Cooling Ducts of Disc Type Transformer Windings Using Particle Image Velocimetry," Electr. Ins. Magazine, 2018 (submitted)

[19] X. Zhang, M. Daghrah, Z. Wang, Q. Liu, P. Jarman, and M. Negro, "Experimental Verification of Dimensional Analysis Results on Flow Distribution and Pressure Drop for Disc-Type Windings in OD Cooling Modes," IEEE. Trans. Power. Del., vol. 33, no. 4, pp. 1647-1656, 2018.

20] Available: http://www.nynas.com/en/product-areassolutions/transformer-oils/oils/nytro-gemini-x/ (2017)

[21] Available: http://www.shell.com/business-customers/lubricantsfor-business/shell-diala-electrical-oils.html (2017)

[22] Available: http://www.midel.com/productsmidel/midel7131/thermal-properties (2017)

[23] M. Pivrnec, P. Allen, K. Havliček, "Calculation of the forced, direcred oil-circulation rate through a transformer cooling systems," in IEEE Proceedings C Generation, Transmission and Distribution, pp. 306-312, 1987
[24] A. Weinläder, W. Wu, S. Tenbohlen, and Z.D Wang, "Prediction of the oil flow distribution in oil-immersed transformer windings by network modelling and computational fluid dynamics," IET electric power applications, vol. 6, no. 2, pp. 82-90, 2012.

A. J. Oliver, "Estimation of transformer winding temperatures and coolant flows using a general network method," IEE Proceedings C Generation, Transmission and Distribution, vol. 127, pp. 395405, 1980.

E. Rahimpour, M. Barati, and M. Schäfer, "An investigation of parameters affecting the temperature rise in windings with zigzag cooling flow path," Appl. Therm. Eng., vol. 27, pp. 1923-1930, 2007.

Z. R. Radakovic and M. S. Sorgic, "Basics of detailed thermalhydraulic model for thermal design of oil power transformers," IEEE Tran. Power Del., vol. 25, pp. 790-802, 2010.

Z. Radakovic, U. Radoman, and P. Kostic, "Decomposition of the hot-spot factor," IEEE Tran. Power Del., vol. 30, no. 1, pp. 403411,2015

[29] J. Coddé, W. Van der Veken, and M. Baelmans, "Assessment of a hydraulic network model for zig-zag cooled power transformer windings," Appl. Therm. Eng., vol. 80, pp. 220-228, 2015.

[30] F. Torriano, P. Picher, M. Chaaban, "Numerical investigation of 3D flow and thermal effects in a disc-type transformer winding," Appl. Therm. Eng., vol. 40, pp. 121-131, 201

[31] A. Skillen, A. Revell, H. Iacovides, and W. Wu, "Numerical prediction of local hot-spot phenomena in transformer windings," Appl. Therm. Eng., vol. 36, pp. 96-105, 2012.

[32] X. Zhang, Z.D Wang, Q. Liu, P. Jarman, and M. Negro, "Numerical investigation of oil flow and temperature distributions for ON transformer windings," Appl. Therm. Eng., vol. 130, pp. 1$9,2018$. 